\title{
Aggressive retinal astrocytoma associated with tuberous sclerosis
}

This article was published in the following Dove Press journal:

Clinical Ophthalmology

8 May 2012

Number of times this article has been viewed

\author{
Machiko Tomida' \\ Yoshinori Mitamura' \\ Takashi Katome' \\ Hiroshi Eguchi' \\ Takeshi Naito' \\ Takayuki Harada ${ }^{2}$ \\ 'Department of Ophthalmology, \\ Institute of Health Biosciences, \\ The University of Tokushima Graduate \\ School, Tokushima, ${ }^{2}$ Visual Research \\ Project, Tokyo Metropolitan Institute \\ of Medical Science, Tokyo, Japan
}

Correspondence: Yoshinori Mitamura Department of Ophthalmology, Institute of Health Biosciences, The University of Tokushima Graduate School, 3-18-15 Kuramoto,

Tokushima 770-8503, Japan

$\mathrm{Tel}+81886337163$

Fax +8I 88 63I 4848

Email ymita@clin.med.tokushima-u.ac.jp
Abstract: We report the case of a patient with an aggressive retinal astrocytoma accompanied with macular edema and neovascular vessels, who was initially treated with intravitreal bevacizumab injections. A 24-year-old male presented to our clinic complaining of visual disturbance in his right eye. At 8 years of age, he had been diagnosed as having tuberous sclerosis complex. Fundus examination demonstrated a retinal tumor accompanied with marked neovascular vessels on the surface, retinal hemorrhage, and macular edema. After six monthly intravitreal bevacizumab injections, fundus examination demonstrated marked regression of the macular edema and neovascular vessels. Two months later, a vitreous hemorrhage developed which necessitated pars plana vitrectomy. After additional intravitreal bevacizumab injection for preventing intraoperative bleeding, vitrectomy with endophotocoagulation for the tumor was performed. The vitreous sample was obtained during vitrectomy, and we measured the vascular endothelial growth factor concentration by enzyme-linked immunosorbent assay. The surgically removed epiretinal neovascular membrane and biopsied retinal tumor expressed vascular endothelial growth factor, although several intravitreal bevacizumab injections led to a vitreous vascular endothelial growth factor concentration of undetectable levels. The clinical course and immunohistochemical analyses indicate that intravitreal bevacizumab monotherapy may have been insufficient to treat the aggressive retinal astrocytoma with macular edema and that laser photocoagulation or photodynamic therapy for the tumor should be considered following intravitreal bevacizumab injection in such cases.

Keywords: aggressive retinal astrocytoma, bevacizumab, macular edema, tuberous sclerosis, vitrectomy, vitreous hemorrhage

\section{Introduction}

Retinal astrocytoma associated with tuberous sclerosis complex is a relatively static lesion with little potential for aggressive behavior. Aggressive retinal astrocytoma associated with tuberous sclerosis complex is a rare variant of this usually benign astrocytoma, and the tumor enlarges progressively, leading to complications, including exudative retinal detachment, vitreous hemorrhage, and neovascular glaucoma. ${ }^{1,2}$ It has been reported that aggressive retinal astrocytoma can be treated with laser photocoagulation, photodynamic therapy, or intravitreal bevacizumab injection..$^{2-7}$ Herein, we report the case of a patient with aggressive retinal astrocytoma and macular edema who was initially treated with intravitreal bevacizumab injection. However, after six monthly intravitreal bevacizumab injections, vitreous hemorrhage developed which necessitated vitrectomy with endophotocoagulation. The surgically removed epiretinal membrane and biopsied retinal tumor expressed vascular endothelial growth factor (VEGF) despite preceding intravitreal bevacizumab injection. 


\section{Case report}

A 24-year-old male presented to our clinic complaining of visual disturbance in his right eye. At 8 years of age, he had been diagnosed as having tuberous sclerosis complex. He had mental retardation, a medical history of epilepsy, and obvious facial angiofibromas. Genetic testing was not performed. The best-corrected visual acuity (BCVA) was 0.09 in the right eye and 1.2 in the left eye. Anterior segments and ocular media were unremarkable in both eyes. The fundus was normal in the left eye. In the right eye, fundus examination demonstrated an elevated lesion in the superior aspect of the optic disc accompanied with marked neovascular vessels on the surface, retinal hemorrhage, and macular edema (Figure 1A). Fluorescein angiography revealed marked leakage from the neovascular vessels (Figure 1B). Spectral-domain optical coherence tomographic (OCT) imaging through the fovea showed a serous retinal detachment (Figure 1C). An aggressive retinal astrocytoma was suspected, and six monthly intravitreal bevacizumab injections $(1.25 \mathrm{mg})$ were performed after informed consent following institutional review board approval.

After the six monthly intravitreal bevacizumab injections, the BCVA improved to 0.3. Fundus examination demonstrated marked regression of neovascular vessels, retinal hemorrhage, and exudative change (Figure 2A). Fluorescein angiography revealed decreased leakage from neovascular vessels (Figure 2B). OCT imaging through the fovea showed disappearance of the serous retinal detachment (Figure 2C). OCT imaging through the elevated lesion showed an epiretinal membrane and retinal tumor located on the retinal surface (Figure 2D).

Two months later, dense vitreous hemorrhage developed, and the BCVA decreased to hand motion. Three days after additional intravitreal bevacizumab injection to prevent intraoperative bleeding, vitrectomy with endophotocoagulation was performed. After the epiretinal neovascular membrane was peeled off, a soft, gelatinous, light grey mass without signs of calcification was found on the retinal surface. The surface of the retinal tumor was biopsied after obtaining informed consent. Histopathologic analysis of the retinal tumor revealed plump spindle-shaped cells with round or slightly elongated nuclei (Figure 3). The retinal tumor was intensely immunoreactive for vimentin, glial fibrillary acidic protein (GFAP), and neuron-specific enolase, being consistent with a diagnosis of astrocytoma ${ }^{1}$ (Figure 4A-C). Despite the preceding intravitreal bevacizumab injections, the tumor also showed immunoreactivity for VEGF (Figure 4D). Immunohistochemical analysis of the surgically removed epiretinal membrane demonstrated coexpression of VEGF and von Willebrand factor, indicating the presence of VEGF in the vascular endothelial cells (Figure 5). A vitreous sample was obtained during vitrectomy, and we also measured the VEGF concentration in the vitreous fluid by enzyme-linked immunosorbent assay (GE Healthcare, Little Chalfont, UK).

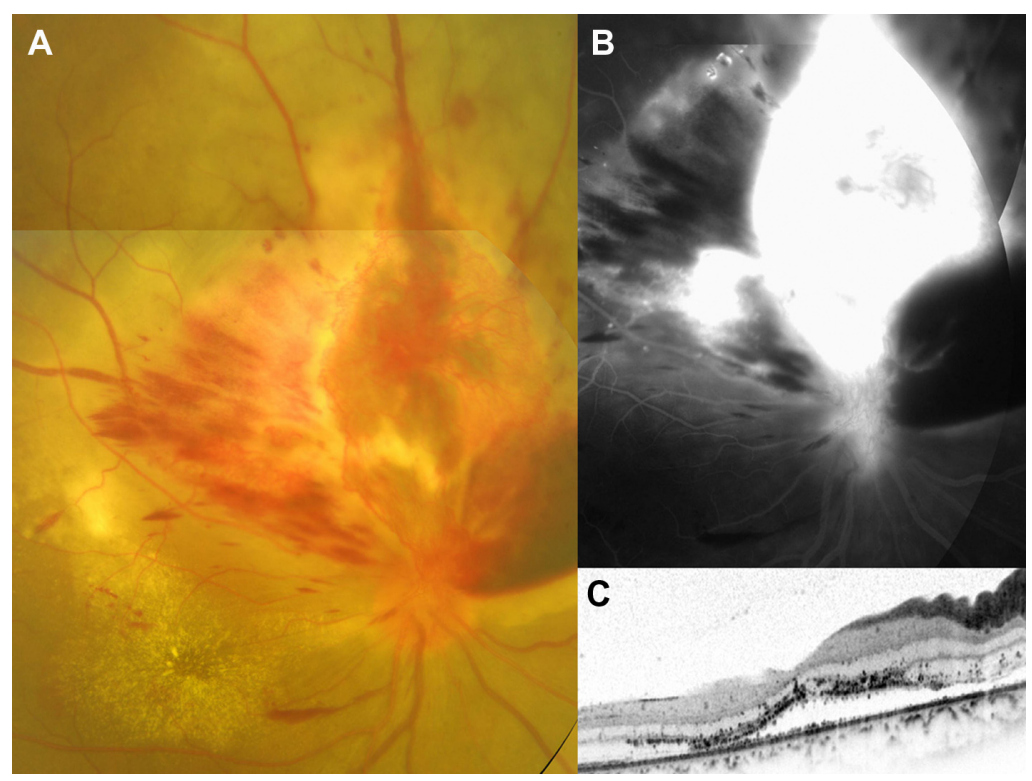

Figure I Color fundus photograph, fluorescein angiographic image, and spectral-domain optical coherence tomographic image at the initial visit for a 24 -year-old man with aggressive retinal astrocytoma. The best-corrected visual acuity was 0.09 . (A) Fundus photograph demonstrates an elevated lesion in the superior aspect of the optic disc accompanied with marked neovascular vessels located on the surface, retinal hemorrhage, and exudative change. Hard exudates are seen in the macula. (B) Late-phase fluorescein angiography reveals marked leakage from the neovascular vessels. (C) Horizontal optical coherence tomographic image through the fovea shows serous retinal detachment. 




Figure 2 Color fundus photograph, fluorescein angiographic image, and spectral-domain optical coherence tomographic (OCT) images after six intravitreal injections of bevacizumab. The best-corrected visual acuity improved to 0.3. (A) Fundus photograph demonstrates marked regression of neovascular vessels, retinal hemorrhage, and exudative change. The direction of the OCT scan is indicated by a white arrow (C) or a black arrow (D). (B) Late-phase fluorescein angiography reveals decreased leakage from neovascular vessels. (C) Horizontal OCT image through the fovea shows disappearance of the serous retinal detachment. (D) Vertical OCT image through the elevated lesion shows a retinal tumor located on the retinal surface (black arrowhead) and epiretinal membrane (white arrowhead).

The vitreous VEGF concentration measured by enzyme-linked immunosorbent assay was at undetectable levels. Clinical and pathological findings are summarized in Table 1.

Two months after vitrectomy, the BCVA recovered to 0.2 . Fundus examination revealed photocoagulation scars corresponding to retinal astrocytoma, and OCT imaging showed

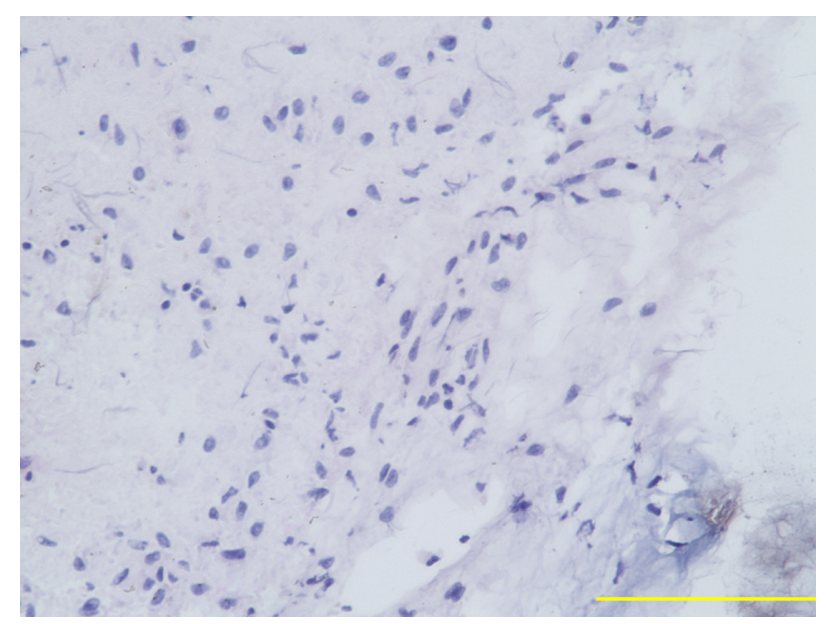

Figure 3 Histopathologic analysis of a biopsy sample of the retinal tumor which was obtained during pars plana vitrectomy.

Notes: Plump spindle-shaped cells with round or slightly elongated nuclei are observed. Mitotic activity is not evident. Hematoxylin-eosin staining was used. Yellow bar represents $100 \mu \mathrm{m}$. no serous macular detachment (Figure 6). Intraocular pressure remained normal at all times, with no evidence of iris neovascularization.

\section{Discussion}

Shields et $\mathrm{al}^{1}$ reported four patients with aggressive retinal astrocytoma associated with tuberous sclerosis complex. All cases had multiple tumors in the fundus. In every case, only one larger tumor near the optic disc showed progressive growth and retinal detachment, whereas all other tumors remained static. An aggressive tumor was also located near the disc in our patient. Shields et $\mathrm{al}^{1}$ reported that aggressive retinal astrocytoma was composed of two types of cells, ie, plump spindle cells and giant cells occasionally with vacuolated cytoplasm. All tumors coexpressed neuron-specific enolase and GFAP. In general the giant cells were immunoreactive for neuron-specific enolase but were negative or only minimally reactive for GFAP. In contrast, the spindle cells expressed both neuron-specific enolase and GFAP. The tumor cells were also strongly immunoreactive for S-100 protein and vimentin. In our present case, histopathologic analysis of the biopsied retinal tumor revealed plump spindle-shaped cells and intense immunoreactivity for vimentin, GFAP, and neuron-specific enolase (Table 1). 


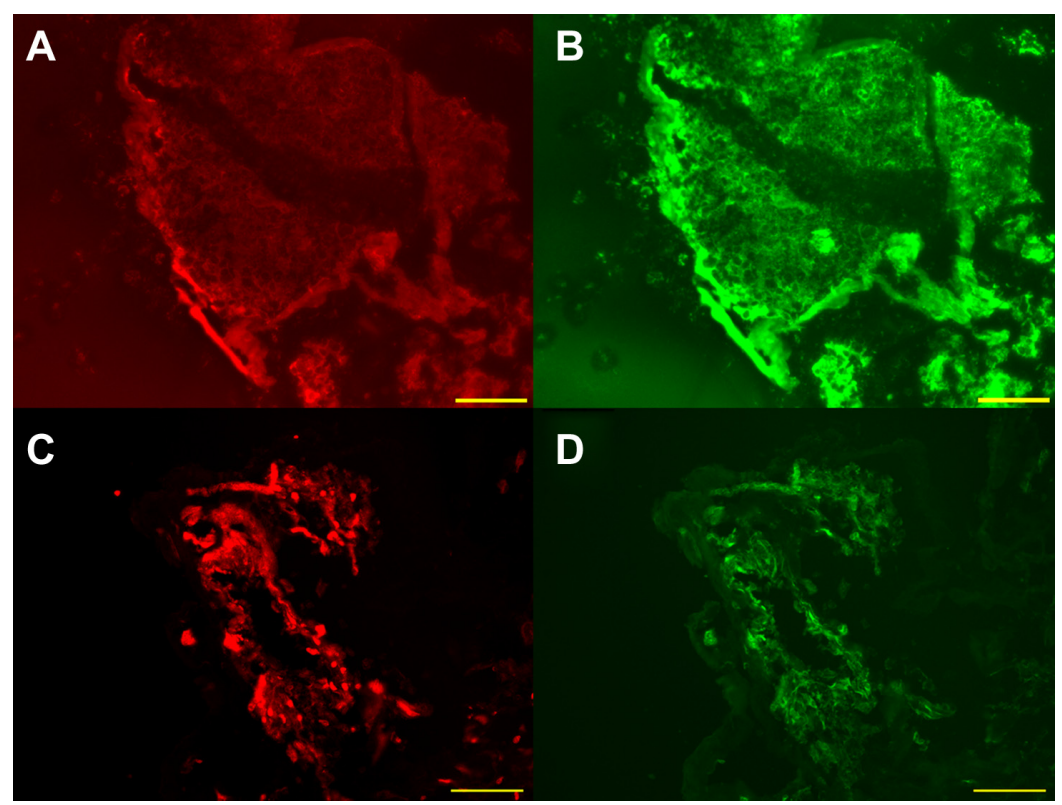

Figure 4 Immunoreactivity of biopsy sample of retinal tumor for vimentin (A), glial fibrillary acidic protein (B), neuron-specific enolase, (C), and vascular endothelial growth factor (D).

Notes: The biopsy sample is intensely immunoreactive for vimentin, glial fibrillary acidic protein, and neuron-specific enolase, being consistent with the diagnosis of astrocytoma. The sample also shows moderate immunoreactivity for vascular endothelial growth factor. Yellow bar represents $100 \mu \mathrm{m}$.

Mennel et $\mathrm{al}^{2}$ published an evidence-based review evaluating the incidence of symptomatic retinal astrocytoma. According to their analyses, symptomatic changes were described in 11 case reports published over a period of three decades. The symptomatic alterations were caused by an enlarged tumor with leakage, macular edema, accumulating lipoid exudates, serous retinal detachment (eight eyes), and vitreous hemorrhage (four eyes). Interventional studies showed slow resorption of subretinal fluid after argon laser photocoagulation (two eyes), although recurrent laser applications induced choroidal neovascularization and destruction of the neurosensory retina (one eye). Vitrectomy was used



Figure 5 Immunoreactivity of surgically removed epiretinal membrane for vascular endothelial growth factor (A) and von Willebrand factor (B). (C) Nuclear staining of the same section. (D) Triple labeling.

Notes: Despite intravitreal bevacizumab injections, triple labeling demonstrates coexpression of vascular endothelial growth factor and von Willebrand factor, indicating the presence of vascular endothelial growth factor in vascular endothelial cells. Yellow bar represents $100 \mu \mathrm{m}$. 
Table I Clinical and pathological findings

\begin{tabular}{|c|c|}
\hline & Findings \\
\hline \multicolumn{2}{|l|}{ Clinical course } \\
\hline Immediately after six IVBs & $\begin{array}{l}\text { Marked regression of neovasclar } \\
\text { vessels and exudative change }\end{array}$ \\
\hline Two months after six IVBs & $\begin{array}{l}\text { Development of vitreous } \\
\text { hemorrhage }\end{array}$ \\
\hline \multicolumn{2}{|l|}{ Retinal tumor } \\
\hline Histopathologic analysis & $\begin{array}{l}\text { Plump spindle-shaped cells with } \\
\text { round or slightly elongated nuclei }\end{array}$ \\
\hline $\begin{array}{l}\text { Immunoreactivity for vimentin, } \\
\text { GFAP, NSE }\end{array}$ & Intensely positive \\
\hline $\begin{array}{l}\text { Immunoreactivity for VEGF } \\
\text { (after IVB) }\end{array}$ & Moderately positive \\
\hline $\begin{array}{l}\text { Immunoreactivity for vimentin, } \\
\text { GFAP, NSE, S-IOO }\end{array}$ & Positive (Shields et al') \\
\hline ( 4 cases reported by Shields et al') & \\
\hline \multicolumn{2}{|l|}{ Epiretinal membrane } \\
\hline $\begin{array}{l}\text { Immunoreactivity for VEGF } \\
\text { (after IVB) }\end{array}$ & $\begin{array}{l}\text { Moderately positive (coexpression } \\
\text { with von Willebrand factor) }\end{array}$ \\
\hline \multicolumn{2}{|l|}{ Vitreous VEGF concentration } \\
\hline After IVB & Under detectable levels \\
\hline $\begin{array}{l}\text { Before IVB (one case reported } \\
\text { by Saito et } a l^{3} \text { ) }\end{array}$ & $\begin{array}{l}68.5 \mathrm{pg} / \mathrm{mL} \text { (higher than levels in } \\
\text { control; Saito et } \mathrm{a}^{3} \text { ) }\end{array}$ \\
\hline
\end{tabular}

Abbreviations: IVB, intravitreal bevacizumab injection; GFAP, glial fibrillary acidic protein; NSE, neuron-specific enolase; VEGF, vascular endothelial growth factor; S-100, S- 100 protein.

to remove a vitreous hemorrhage in one patient. In one case, complete resorption of subretinal fluid and an increase in visual acuity was observed within 2 weeks after a single treatment with photodynamic therapy.

Saito et $\mathrm{al}^{3}$ reported that macular edema secondary to aggressive retinal astrocytoma resolved after intravitreal bevacizumab injection in two cases. Similarly, macular edema regressed remarkably after monthly intravitreal bevacizumab injections in our present case. These results suggest that VEGF derived from retinal astrocytoma causes macular edema and that intravitreal bevacizumab injection is effective for resolving the macular edema temporarily. It has been shown that hamartomas associated with tuberous sclerosis complex involving organs other than the eyes (kidney, brain, and skin) are highly angiogenic and may express VEGF. ${ }^{3,8,9}$ As far as we know, there are no reports regarding VEGF expression in the tumor of aggressive retinal astrocytoma, although the vitreous VEGF concentration has been reported to be high in aggressive retinal astrocytoma (Table 1). ${ }^{3}$ In the present study, we showed VEGF expression in both retinal tumor and epiretinal membrane. Therefore, VEGF derived from aggressive retinal astrocytoma may play a potential role in the pathogenesis of macular edema, exudative retinal detachment, and epiretinal neovascular membrane secondary to tuberous sclerosis complex. Saito

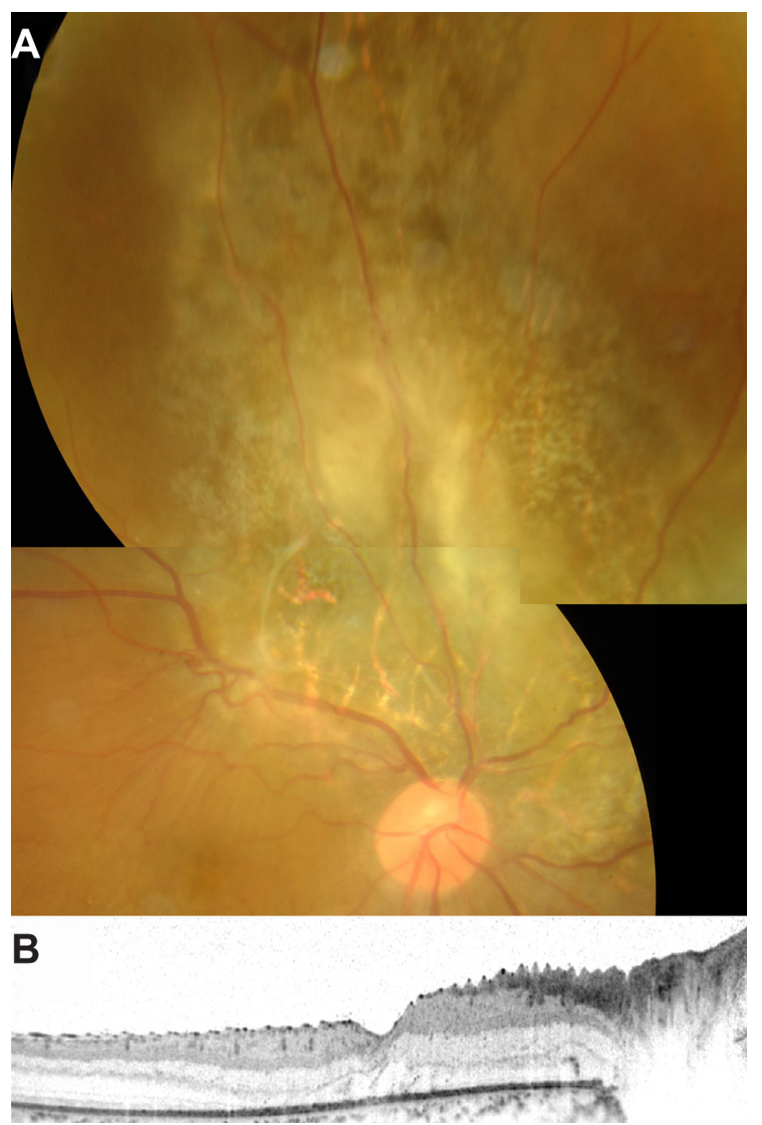

Figure 6 Color fundus photograph and spectral-domain optical coherence tomographic image after pars plana vitrectomy. The best-corrected visual acuity was 0.2. (A) Fundus photograph demonstrates retinal photocoagulation scars corresponding to retinal astrocytoma. Small residual retinal astrocytoma is seen in the center of the photocoagulation scars. (B) Horizontal optical coherence tomographic image through the fovea shows no serous retinal detachment.

et $\mathrm{al}^{3}$ reported that macular edema recurred after intravitreal bevacizumab injection in one of two cases and that recurrent edema was successfully treated by additional laser photocoagulation to the tumors. In the other case, the small tumor size might have been one of the causes of no recurrence of macular edema after intravitreal bevacizumab injection. In our case, vitreous hemorrhage developed after intravitreal bevacizumab injection, which necessitated vitrectomy with endophotocoagulation. Several intravitreal bevacizumab injections led to an undetectable vitreous VEGF concentration. Despite the preceding intravitreal bevacizumab injections, the surgically removed epiretinal membrane and biopsied retinal tumor expressed VEGF. These results suggest that intravitreal bevacizumab injection is effective for reducing the vitreous VEGF concentration but insufficient for completely inhibiting VEGF activity in the tumor. Therefore, macular edema or neovascularization may recur frequently after intravitreal bevacizumab monotherapy. The clinical course and immunohistochemical analyses in our 
patient indicate that intravitreal bevacizumab monotherapy may have been insufficient to treat aggressive retinal astrocytoma with macular edema, and that laser photocoagulation or photodynamic therapy for the tumor should be considered following intravitreal bevacizumab injection. However, we cannot clarify whether combined therapy of intravitreal bevacizumab injection and laser photocoagulation or photodynamic therapy is more effective than photodynamic therapy alone or not. Accumulation of treated cases with aggressive retinal astrocytoma is necessary.

Aggressive retinal astrocytoma shows progressive enlargement of the tumor accompanied by total exudative retinal detachment and neovascular glaucoma. ${ }^{1}$ Without adequate treatment, enucleation eventually becomes necessary because of blindness and ocular pain. ${ }^{1}$ Therefore, precise diagnosis and prompt treatment are important. In our present case, final visual acuity remained at 0.2 , presumably because of longstanding macular edema at the initial visit. When we follow up patients with tuberous sclerosis complex, detecting initial or recurrent macular edema by performing OCT in the early stages is mandatory for preventing a poor visual prognosis. $^{3}$

\section{Disclosure}

The authors did not receive grant support or research funding for this work, and do not have any proprietary interests in the materials described in this paper.

\section{References}

1. Shields JA, Eagle RC Jr, Shields CL, Marr BP. Aggressive retinal astrocytomas in 4 patients with tuberous sclerosis complex. Arch Ophthalmol. 2005;123(6):856-863.

2. Mennel S, Meyer CH, Peter S, Schmidt JC, Kroll P. Current treatment modalities for exudative retinal hamartomas secondary to tuberous sclerosis: review of the literature. Acta Ophthalmol Scand. 2007;85(2):127-132.

3. Saito W, Kase S, Ohgami K, Mori S, Ohno S. Intravitreal anti-vascular endothelial growth factor therapy with bevacizumab for tuberous sclerosis with macular oedema. Acta Ophthalmol. 2010;88(3): 377-380.

4. Bloom SM, Mahl CF. Photocoagulation for serous detachment of the macula secondary to retinal astrocytoma. Retina. 1991;11(4):416-422.

5. Eskelin S, Tommila P, Palosaari T, Kivelä T. Photodynamic therapy with verteporfin to induce regression of aggressive retinal astrocytomas. Acta Ophthalmol. 2008;86(7):794-799.

6. Mennel S, Hausmann N, Meyer CH, Peter S. Photodynamic therapy for exudative hamartoma in tuberous sclerosis. Arch Ophthalmol. 2006; 124(4):597-599.

7. Shields CL, Materin MA, Marr BP, Krepostman J, Shields JA. Resolution of exudative retinal detachment from retinal astrocytoma following photodynamic therapy. Arch Ophthalmol. 2008;126(2):273-274.

8. Nguyen-Vu PA, Fackler I, Rust A, et al. Loss of tuberin, the tuberoussclerosis-complex-2 gene product is associated with angiogenesis. J Cutan Pathol. 2001;28(9):470-475.

9. Arbiser JL, Brat D, Hunter S, et al. Tuberous sclerosis-associated lesions of the kidney, brain, and skin are angiogenic neoplasms. J Am Acad Dermatol. 2002;46(3):376-380.
Clinical Ophthalmology

\section{Publish your work in this journal}

Clinical Ophthalmology is an international, peer-reviewed journal covering all subspecialties within ophthalmology. Key topics include: Optometry; Visual science; Pharmacology and drug therapy in eye diseases; Basic Sciences; Primary and Secondary eye care; Patient Safety and Quality of Care Improvements. This journal is indexed on Submit your manuscript here: http://www.dovepress.com/clinical-ophthalmology-journal

\section{Dovepress}

PubMed Central and CAS, and is the official journal of The Society of Clinical Ophthalmology (SCO). The manuscript management system is completely online and includes a very quick and fair peer-review system, which is all easy to use. Visit http://www.dovepress.com/ testimonials.php to read real quotes from published authors. 